\title{
Analysis of Hysteresis-Free Creep of the Stack Piezoelectric Actuator
}

\author{
Xueliang Zhao, ${ }^{1,2}$ Chengjin Zhang, ${ }^{3}$ Hongbo Liu, ${ }^{1}$ Guilin Zhang, ${ }^{1}$ and Kang Li ${ }^{1}$ \\ ${ }^{1}$ School of Control Science and Engineering, Shandong University, Jinan, Shandong 250061, China \\ ${ }^{2}$ School of Information Engineering, Taishan Medical University, Taian, Shandong 271016, China \\ ${ }^{3}$ School of Mechanical, Electrical \& Information Engineering, Shandong University at Weihai, Shandong 264209, China \\ Correspondence should be addressed to Chengjin Zhang; cjzhang@sdu.edu.cn
}

Received 8 March 2013; Accepted 22 April 2013

Academic Editor: Qingsong Xu

Copyright (C) 2013 Xueliang Zhao et al. This is an open access article distributed under the Creative Commons Attribution License, which permits unrestricted use, distribution, and reproduction in any medium, provided the original work is properly cited.

A modified log-type creep model without hysteresis of the stack piezoelectric actuator is presented. For high-speed micro/nanopositioning system, the time scale should be less than one second for creep modeling and control in the stack piezoelectric actuator. But creep effect was studied in the frame of minutes in previous works. Meanwhile, parameters of the classical creep models are hard to be determined. By the proposed model, the hysteresis and the creep effect can be separated. A series of experiments have been performed, where different staircase voltages have been applied to the actuator. There are two clear rules to follow in small duration and different heights to determine parameters. Firstly, $L_{0}$ starts from fixed point either in ascending stage or in descending stage and rotates clockwise. Secondly, $\gamma$ converges to a small vicinity of a constant when the duration is small enough.

\section{Introduction}

The applications of piezoelectric (PZT) actuators are restricted by their nonlinearities, such as hysteresis [1-3] and creep $[4,5]$. Hysteresis has bigger influence on PZT actuators than creep has, but creep deteriorates the positioning accuracy apparently over extended period of time [6].

Two methods were applied to compensate for the creep effect. Firstly, the effect can be suppressed by some complex algorithms in the closed loop [7-9]. But this method requires expensive devices in order to achieve fast data acquisition and high-speed computation. Secondly, creep models and their inverse models were cascaded to compensate for the creep. Some phenomenological creep models were used in the open loop, such as log-type $[5,10,11]$ and LTI [6]. However, parameters in these models are complex hysteretic [12]. Considering hysteresis as an accurate nonlinearity, some creep operators coupled with hysteresis were proposed in $[13,14]$. To compensate for the time-dependent and voltagedependent creep effect, Kuhnen and Krejci [15] proposed a complex threshold discrete Preisach operator and its inverse operator, in which the creep was closely related to the hysteresis. Its dynamic property was verified in [16]. Moreover, a creep model with the Prandtl-Ishlinskii (PI) operator was presented in [17]. Other models from the view of materials were presented in [18-20].

Comparing to the voltage control, charge control was used to suppress hysteresis and creep effects to a large extend in $[21,22]$. Switched capacitor charge pump control was presented in [23] to reduce the creep as an effective way. However self-discharge, small current in low dynamic positioning, and external misaligning effect limit the application of charge control.

The creep is a slow and smooth process [12]. However the requirement of high-speed nanopositioning propels the control duration down to one second. In other words, control duration has been shortened. Hence it becomes meaningful to find properties of creep in small voltage duration. Krejci and Kuhnen [24] gave a figure to describe the creep effect in the small duration of staircase voltage, but more interpretations should be given. A dynamic electromechanical model [25] was presented to model the dynamic creep, but the coupled model was hard to show the special properties of the creep in small duration.

The paper is organized as follows. Section 2 proposes a modified log-type creep model in order to separate the 


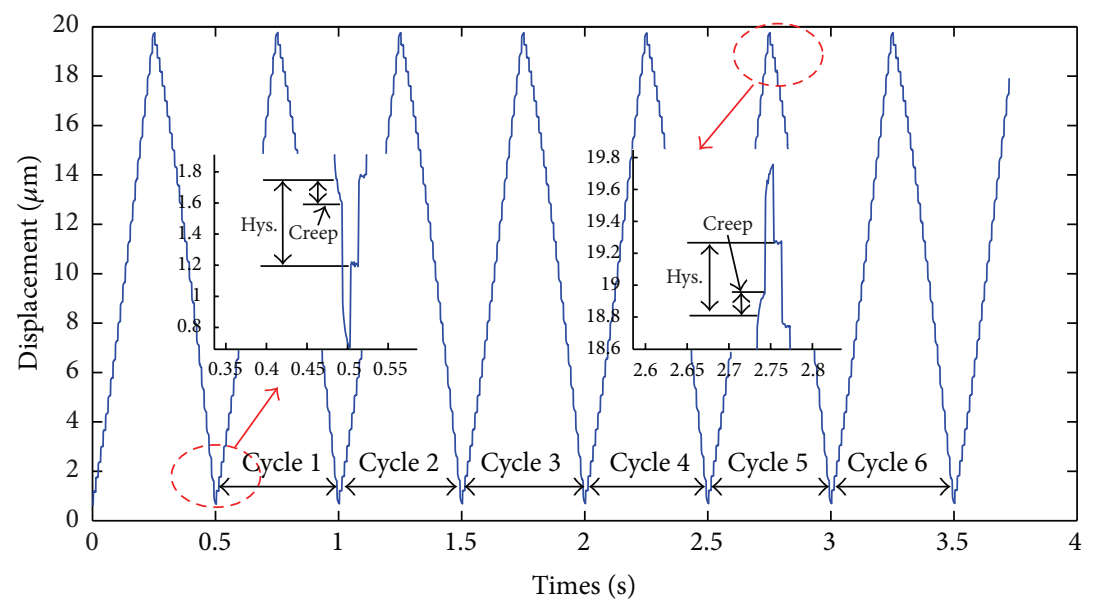

FIGURE 1: Relation between hysteresis and creep in staircase voltage response.

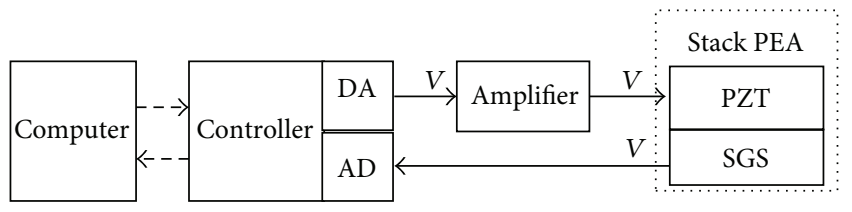

(a)

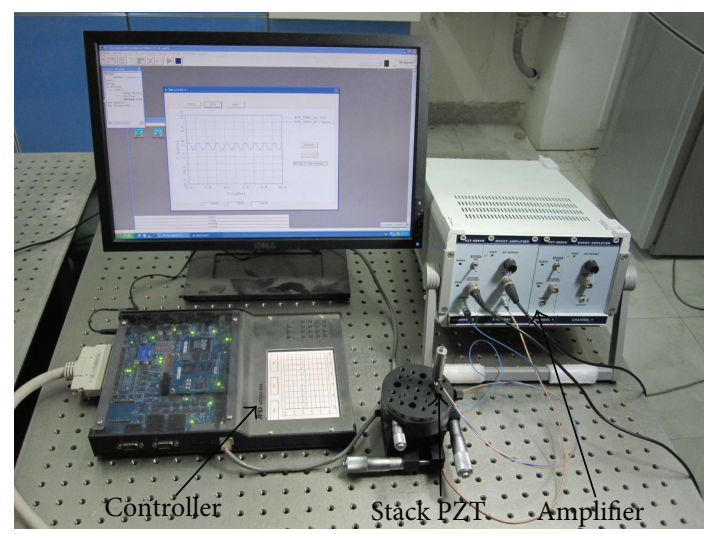

(b)

FIgURE 2: Experimental setup. (a) Structure diagram; (b) experiment devices.

hysteresis and the creep. A series of experiments are designed and performed in Section 3. The section is devoted to observe the influence of the duration and the height of staircase voltages on creep. The identification and the distributing rule of parameters are given in Section 4. Section 5 gives some concluding remarks and discussions.

\section{Creep Modeling}

Figure 1 illustrates the response of PZT actuators for a series of $3 \mathrm{~V}$ staircase input voltages with $0.01 \mathrm{~s}$ duration. The embedded figures show the responses of the maximum step voltage $(75 \mathrm{~V})$ and the minimum step voltage $(0 \mathrm{~V})$. In spite of not having knowledge on the occurring time of hysteresis and transient procedure, creep is defined as a much slower response that happens finally. PZT actuators, with high resonant frequency, are in creep procedure if its response curve under fixed voltage changes smoothly. The descriptive equation of classical log-type creep is given [1].

$$
L(t)=L_{0} \times\left[1+\gamma \times \log _{10}\left(\frac{t}{0.1}\right)\right],
$$

where $L(t)$ is the displacement of PZT actuators for any fixed input voltage, $L_{0}$ is a nominal constant displacement value, and $\gamma$ is the creep factor that determines the rate of the logarithm. In the experiment, under $0.001 \mathrm{~s}$ sampling interval, a dynamic transient was not observed. According to [1], the creep effect continues until the next step voltage is applied. The response of applied staircase voltage after $0.001 \mathrm{~s}$ is the one corresponding displacement of hysteresis.

A modified model of creep is given as the following equation:

$$
\begin{array}{r}
L_{i k}\left(T_{d}\right)=D_{i k}\left(T_{d}\right)-H_{i k}=L_{i k 0} \times\left[1+\gamma_{i k} \times \log _{10}\left(\frac{t}{0.1}\right)\right], \\
i=1,2 ; t \in\left[0, T_{d}\right],
\end{array}
$$

where $i$ is 1 when voltage is in ascending stage and $i$ is 2 when voltage is in descending stage, $L_{i k}\left(T_{d}\right)$ is creep for $i$ th fixed input voltage in $T_{d}$ duration, $D_{i k}\left(T_{d}\right)$ is measured displacement for $k$ th fixed input voltage in $T_{d}$ duration, $H_{i k}$ is the measured displacement of $k$ th step input voltage after $0.001 \mathrm{~s}, L_{i k 0}$ is the creep initial response of $k$ th stair, and $\gamma_{i k}$ is the creep factor, then the displacement of hysteresis is equal to $\left|H_{2 k}-H_{1 k}\right|$. The real creep maybe occurs before $0.001 \mathrm{~s}$ after the applied voltage; it has an influence on displacement of creep but not on the variation rules of the creep.

\section{Experimental Setup}

The experiments are performed according to the experiment setup as shown in Figure 2. There is a stack-type 


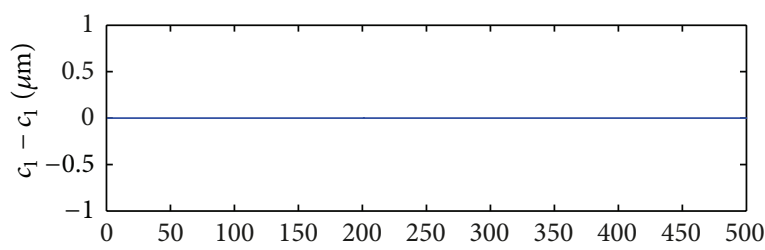

(a)

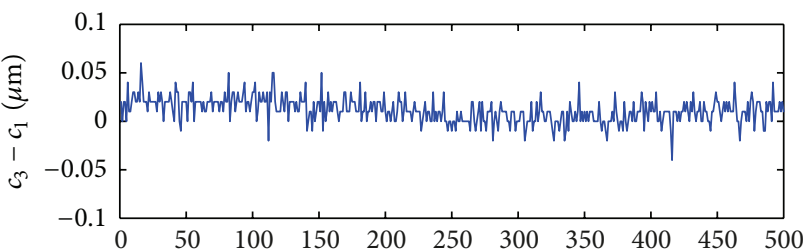

(c)

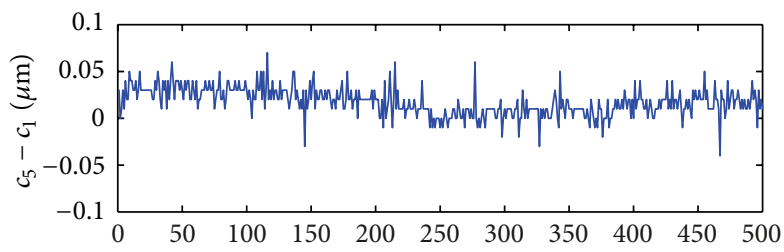

(e)

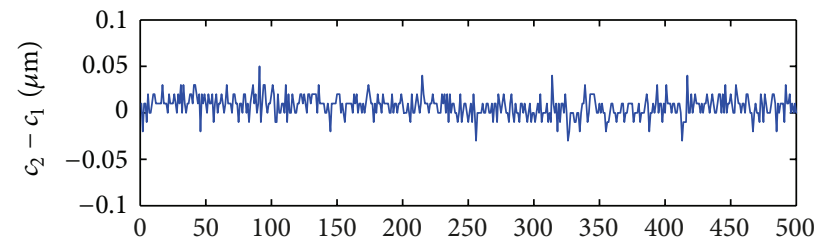

(b)

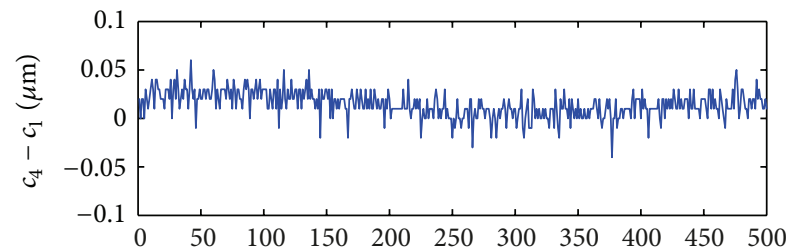

(d)

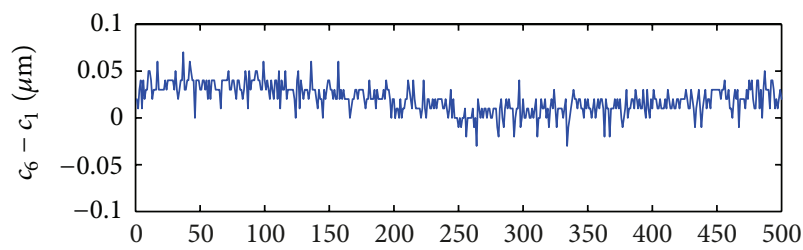

(f)

FiguRE 3: Creep relation with different cycles. (a) cycle 1-cycle 1; (b) cycle 2-cycle 1; (c) cycle3-cycle 1; (d) cycle 4-cycle 1; (e) cycle 5-cycle 1; (f) cycle 6-cycle 1.

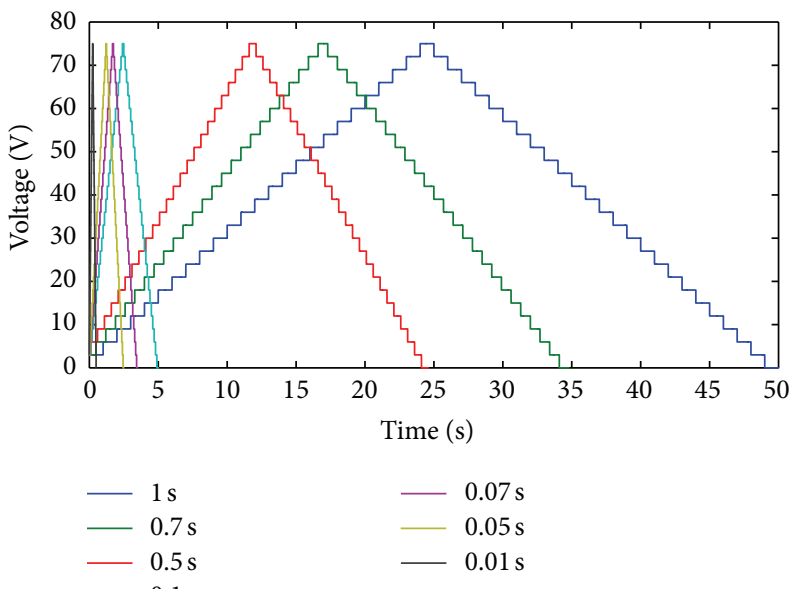

(a)

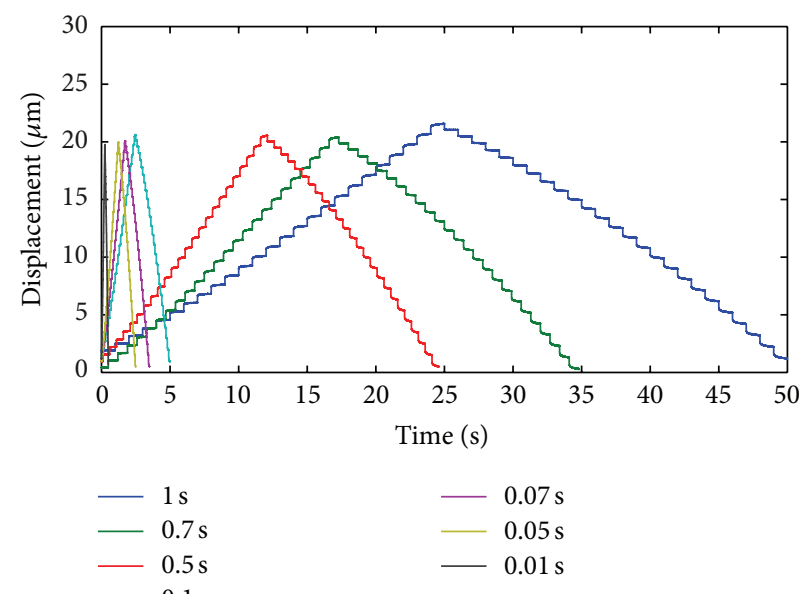

(b)

Figure 4: Different input voltage durations $T_{d}$, where $T_{d} \in(1 \mathrm{~s}, 0.7 \mathrm{~s}, 0.5 \mathrm{~s}, 0.1 \mathrm{~s}, 0.07 \mathrm{~s}, 0.05 \mathrm{~s}, 0.01 \mathrm{~s})$. (a) Staircase input voltage; (b) the response.

high resonant frequency PZT actuator (Pst 150/7/40 VS12, Piezomechanik) with $40 \mu \mathrm{m}$ nominal displacement for $150 \mathrm{~V}$. Controlled signal and data acquisition flow diagram are obtained from the Simulink and then compiled, and downloaded to the controller (AD7011, A \& D). Measured displacement voltage from SGS is transformed linearly.

3.1. Periodic Relation. To investigate whether creep curve has some relation with periodic input voltage, a series of staircase voltages are applied to the PZT actuators. The staircase voltages are of the magnitude of $3 \mathrm{~V}$ and the duration of $0.01 \mathrm{~s}$, and one complete voltage cycle consists of $3 \mathrm{~V}-75 \mathrm{~V}-0 \mathrm{~V}$. In Figure 3, six cycles' displacements are subtracted from the first cycle's displacement.

By using the xcorr function of MATLAB, it is found that cross-correlation of the six cycle curves in Figure 1 are all 1 as lag is 0 . This means that any cycle can stand for the whole properties of creep effect. In order to find the rule of small difference of the six cycles in Figure 3, the mean of these differences is shown in Table 1. 


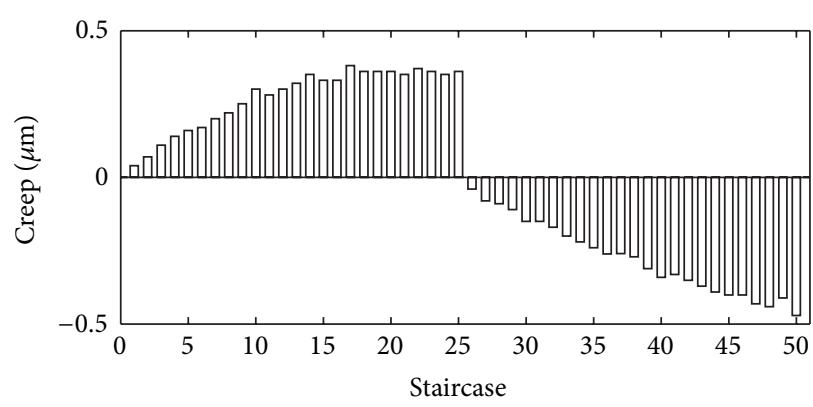

(a)

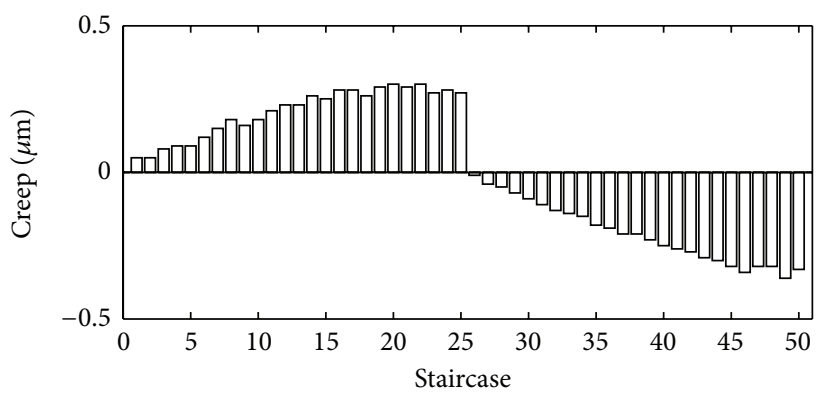

(c)

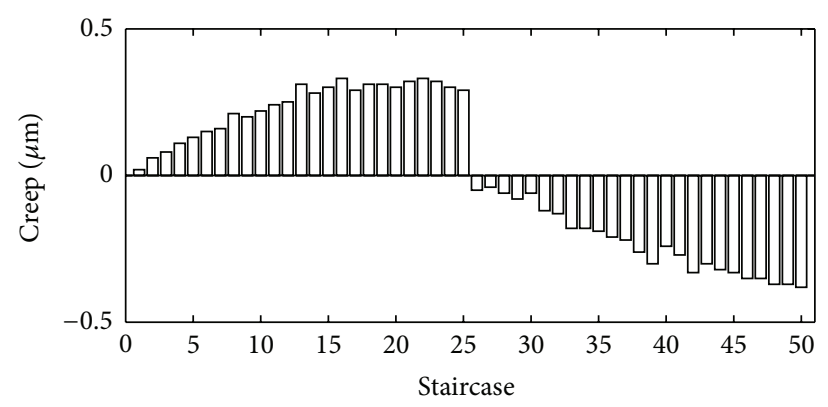

(b)

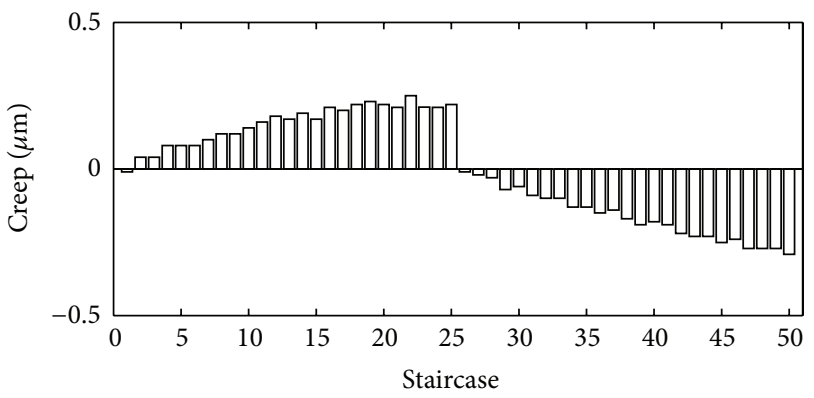

(d)

FIGURE 5: Creep increment of $3 \mathrm{~V}$ staircase input voltage with different durations. (a) $1 \mathrm{~s}$; (b) $0.1 \mathrm{~s}$; (c) $0.05 \mathrm{~s}$; (d) $0.01 \mathrm{~s}$.

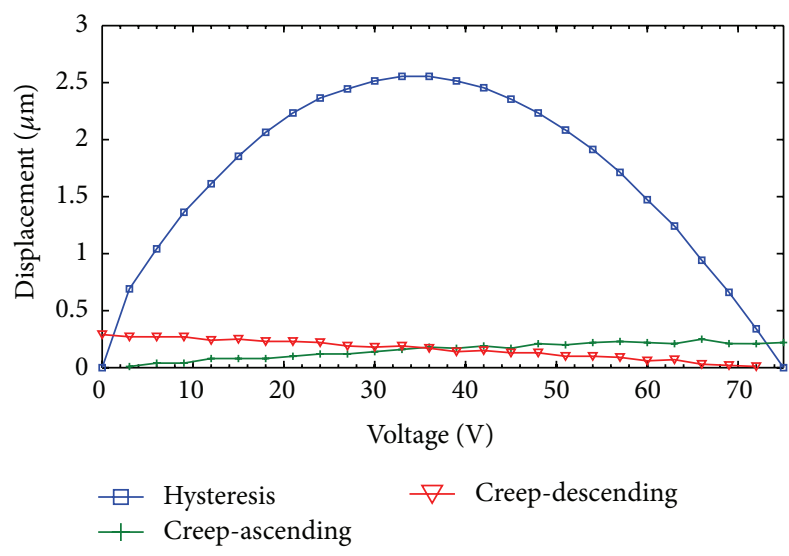

(a)



(b)

FIGURE 6: The input step voltage has $3 \mathrm{~V}$ height and $0.01 \mathrm{~s}$ duration. (a) Hysteresis and creep; (b) ratio of creep to hysteresis.

From Table 1, the mean error of creep displacement is less than $0.020 \mu \mathrm{m}$, and the absolute maximum error is less than $50 \mathrm{~nm}$. The mean is increasing continuously and slightly; it is not clear whether the creep effect or thermal drift has an influence on it.

3.2. Different Durations. From Figure 4, creep displacement is increasing both in ascending stage and in descending stage. So the extreme displacement occurs in the first stair and the last stair to different stages. The absolute maximum creep displacement only occurs at the top or bottom of a staircase, where the controlled input step voltage changes direction in the next step. When controlled voltage changes direction, the direction of creep also changes. Then the changing direction of input voltage resets the creep effect, and the creep displacement will increase from small creep again. With duration decreasing, the frequency of input voltage becomes higher at the same time.

The changes of the extreme displacement are shown in Table 2, in which the height of staircase voltage is $3 \mathrm{~V}$. Although both the minimum displacement and the maximum displacement are decreasing in Table 2, the amount of reduction does not have an apparent rule. In order to find the rule of creep in one cycle, every stair displacement is preprocessed according to (2), in which all those displacements are subtracted by the displacement of $0.001 \mathrm{~s}$. The variations are shown in Figure 5. One cycle, $3 \mathrm{~V}-75 \mathrm{~V}-0 \mathrm{~V}$, is divided into 50 staircases. 


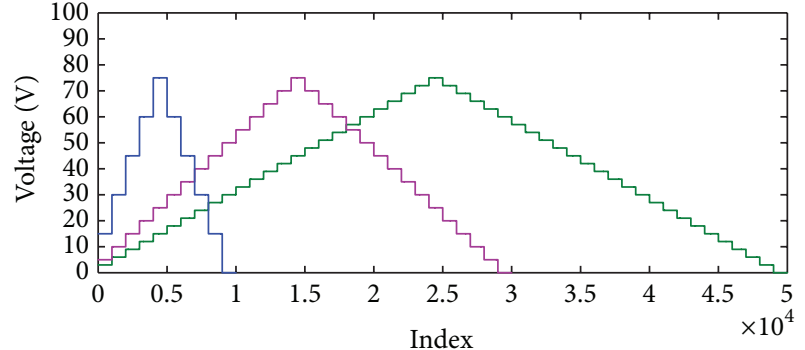

$-3 \mathrm{~V}$
$-5 \mathrm{~V}$

(a)

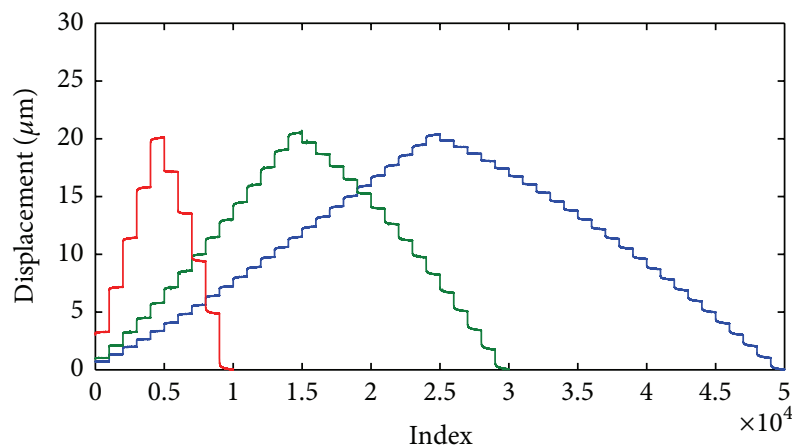

$-3 \mathrm{~V}$

$-15 \mathrm{~V}$

(b)

FIGURE 7: Relationship between input voltage and output displacement. (a) Input voltage; (b) displacement response.

TABLE 1: Mean of difference.

\begin{tabular}{lcc}
\hline No. & Figure 3 & Mean $(\mu \mathrm{m})$ \\
\hline 1 & (a) & 0 \\
2 & (b) & 0.007 \\
3 & (c) & 0.011 \\
4 & (d) & 0.015 \\
5 & (e) & 0.018 \\
6 & (f) & 0.020 \\
\hline
\end{tabular}

TABLE 2: Extreme displacement with different durations.

\begin{tabular}{lccc}
\hline No. & Duration $(\mathrm{s})$ & $\begin{array}{c}\text { Minimum } \\
\text { displacement } \\
(\mu \mathrm{m})\end{array}$ & $\begin{array}{c}\text { Maximum } \\
\text { displacement } \\
(\mu \mathrm{m})\end{array}$ \\
\hline 1 & 1 & 1.191 & 21.892 \\
2 & 0.7 & 0.259 & 20.419 \\
3 & 0.5 & 0.490 & 20.580 \\
4 & 0.1 & 0.911 & 20.650 \\
5 & 0.07 & 0.490 & 20.088 \\
6 & 0.05 & 0.450 & 19.998 \\
7 & 0.01 & 0.640 & 19.767 \\
\hline
\end{tabular}

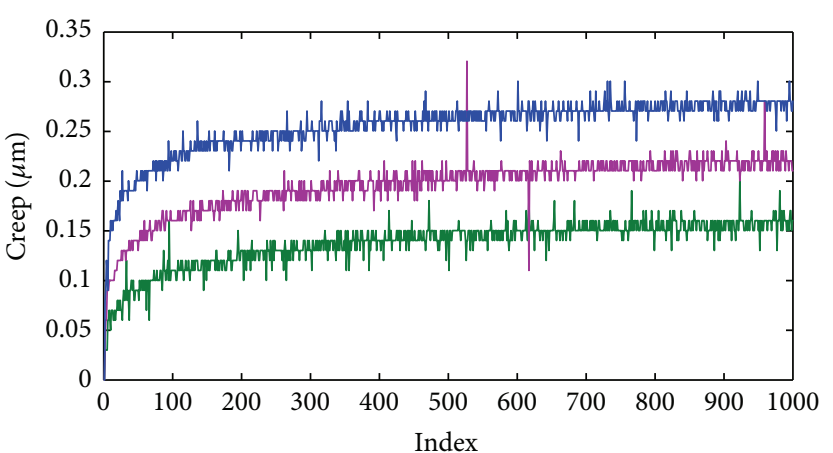

(a)

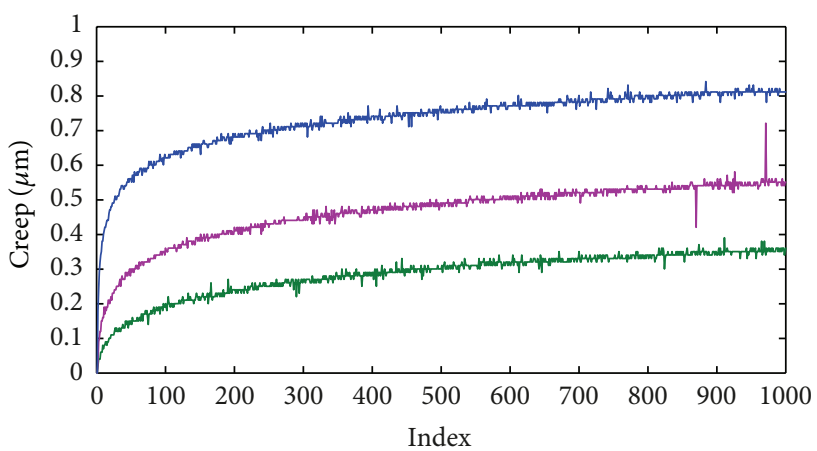

(b)

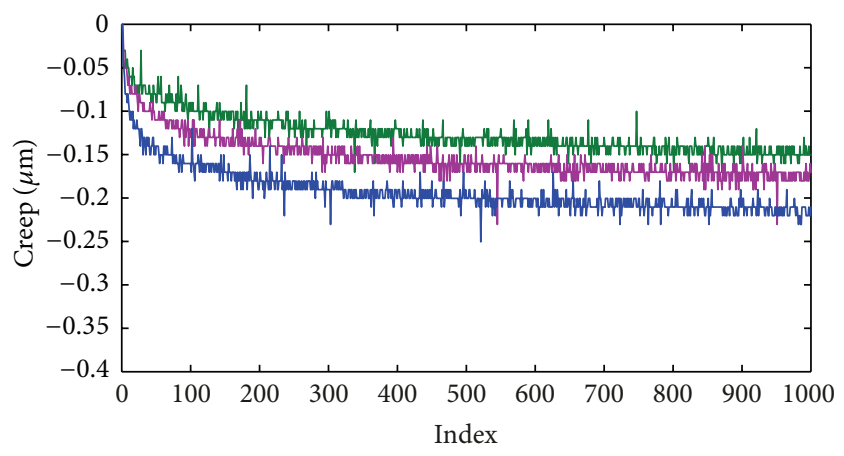

(c)

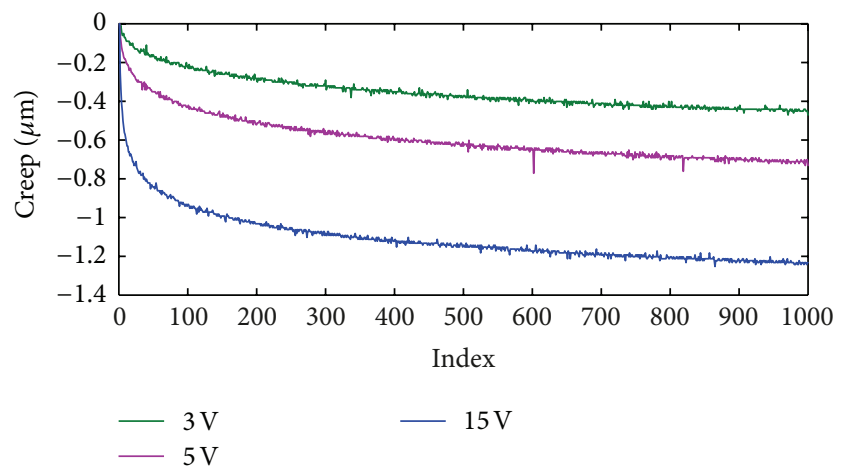

(d)

FIGURE 8: Response of different staircase voltages with different heights influence on the creep: (a) $15 \mathrm{~V}$ in ascending stage; (b) $75 \mathrm{~V}$ in ascending stage; (c) $60 \mathrm{~V}$ in descending stage; (d) $0 \mathrm{~V}$ in descending stage. 


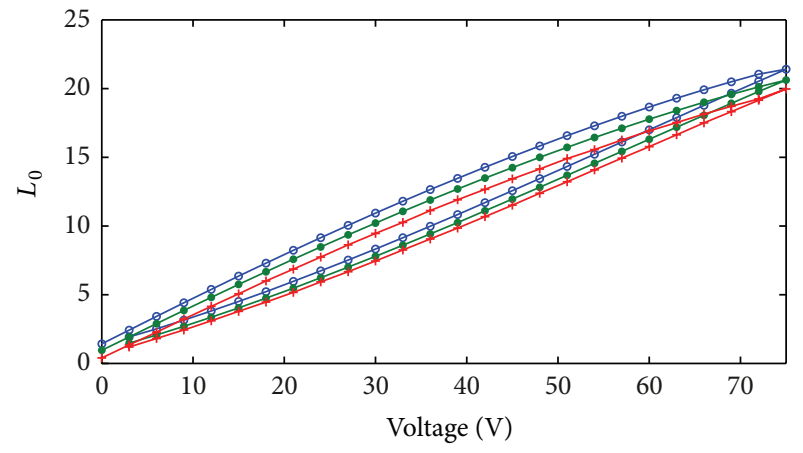

(a)

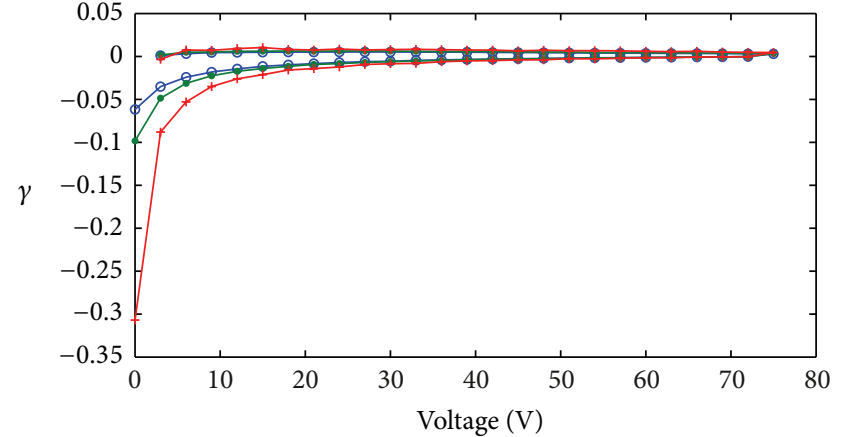

(b)

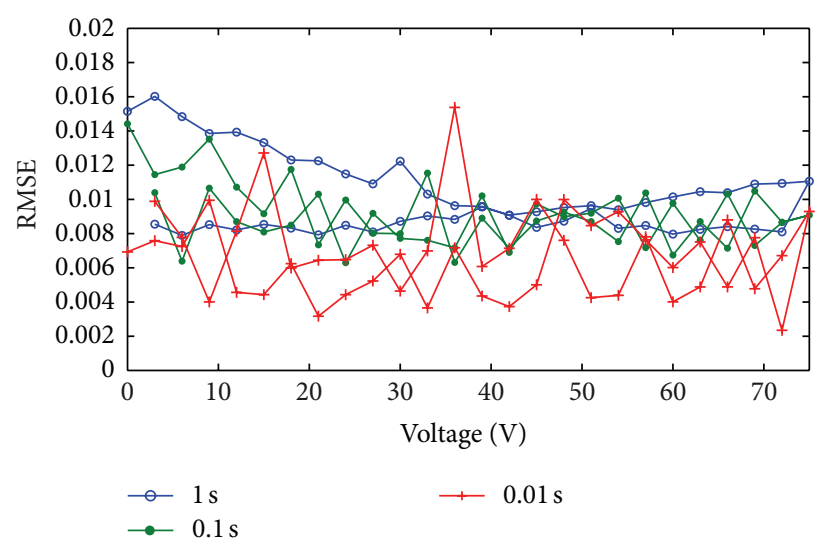

(c)

Figure 9: Parameters distribution of classical log-type creep with $3 \mathrm{~V}$ height and different durations $T_{d}, T_{d} \in(1 \mathrm{~s}, 0.1 \mathrm{~s}, 0.01 \mathrm{~s})$; (a) $L_{0}$; (b) $\gamma$; (c) RMSE.

It is seen from Figure 5 that the creep increment changes with different rates. It is apparent that the smaller duration results in the smaller increment. The creep increment is decreasing, but it obviously exits. The rule of creep increment in ascending stage is different from that in descending stage. The absolute maximum increment of creep is $0.471 \mu \mathrm{m}$, $0.381 \mu \mathrm{m}, 0.331 \mu \mathrm{m}$, and $0.291 \mu \mathrm{m}$ with the duration of $1 \mathrm{~s}$, $0.1 \mathrm{~s}, 0.05 \mathrm{~s}$, and $0.01 \mathrm{~s}$, respectively. The absolute maximum increment of creep all occurs in descending stage. The sum of absolute increment in ascending stage is smaller than that in descending stage when the duration is $1 \mathrm{~s}, 0.05 \mathrm{~s}$, and $0.01 \mathrm{~s}$; however, it is not right when the duration is $0.1 \mathrm{~s}$. Since the sum of absolute increment in ascending stage is smaller than that in descending stage when the duration is $0.01 \mathrm{~s}$, it seems that the mean of one cycle becomes negative after some cycles. It is in contradiction with the result in Figure 3. In fact, the difference between the sum of absolute increment in ascending stage and that in descending stage is smaller than periodic increment.

From (2), hysteresis is zero when input voltage reaches the maximum value and the minimum value, as illustrated in Figure 6(a). The maximum creep displacement is at two endpoints, and at the same time the hysteresis displacement is zero. The hysteresis curve is not symmetric and has faster increasing ratio when input voltage is smaller than $36 \mathrm{~V}$. The ratio of creep and hysteresis is shown in Figure 6(b).
The proportion of creep increases drastically when input voltage is close to the two endpoints.

3.3. Different Heights. In order to investigate the influence on creep with height of input voltage, three staircase voltages with different heights are applied to the PZT actuators. The staircase number is smaller when the height is bigger. To minimize the periodic influence, the second cycle is chosen. Meanwhile all chosen cycle displacements are added to or subtracted from the last sampling displacement of $0 \mathrm{~V}$ in order to keep the same initial displacement. There is no influence on creep by this linear translation. The relation between input voltage and displacement is as shown in Figure 7.

The same voltages, $(15 \mathrm{~V}, 30 \mathrm{~V}, 45 \mathrm{~V}, 60 \mathrm{~V}, 75 \mathrm{~V})$ in ascending stage and $(60 \mathrm{~V}, 45 \mathrm{~V}, 30 \mathrm{~V}, 15 \mathrm{~V}, 0 \mathrm{~V})$ in descending stage, and the corresponding displacement are used to investigate the influence on creep with different heights of input staircase voltages. According to (2), Figure 8 only has creep displacement.

From Figure 8, the height of input voltage has deep influence on the creep. With the height increasing, creep becomes lager. When input voltage is $15 \mathrm{~V}$, the maximum creep displacement reaches $0.200 \mu \mathrm{m}, 0.220 \mu \mathrm{m}$, and $0.301 \mu \mathrm{m}$ as the height of staircase voltage is $3 \mathrm{~V}, 5 \mathrm{~V}$, and $15 \mathrm{~V}$, respectively. The difference of the step response between $3 \mathrm{~V}$ and $5 \mathrm{~V}$, and that 


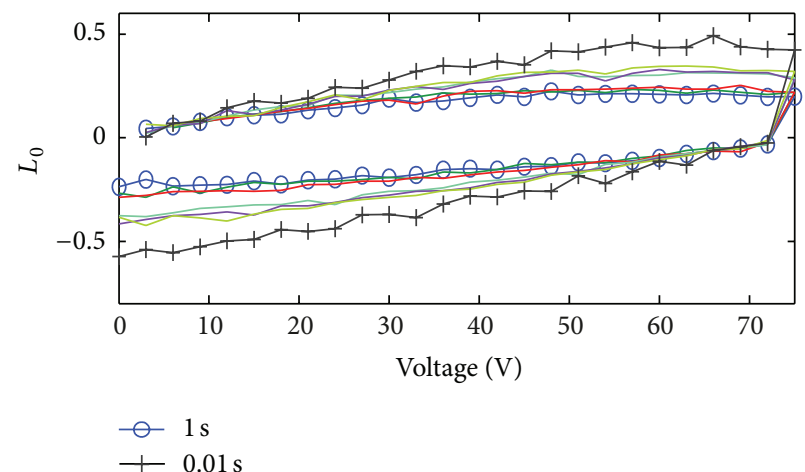

(a)

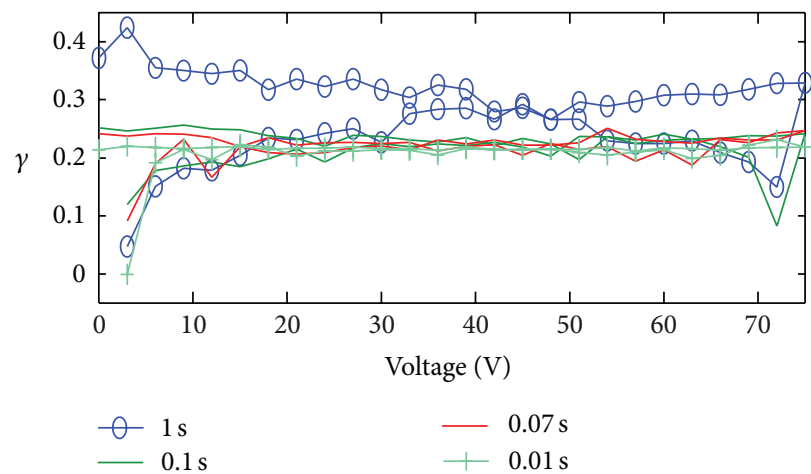

(b)

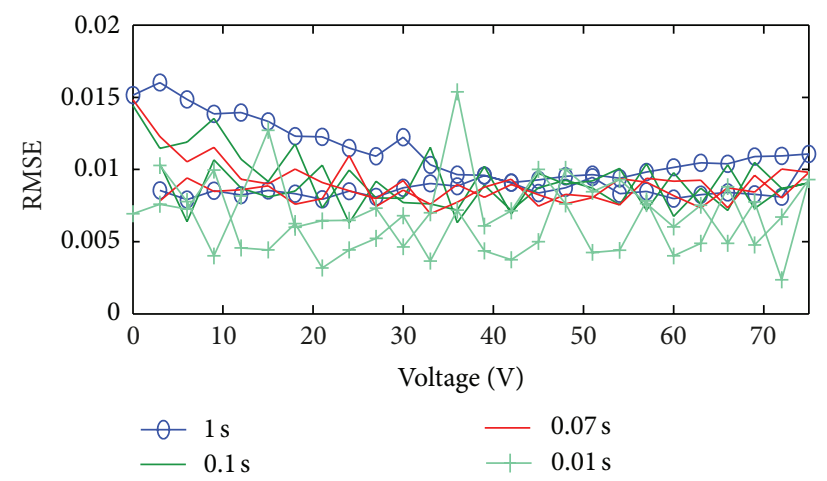

(c)

FIGURE 10: Parameters distribution of the proposed log-type creep as the height is $3 \mathrm{~V}$ and different durations $T_{d}, T_{d} \in(1 \mathrm{~s}, 0.7 \mathrm{~s}, 0.5 \mathrm{~s}, 0.1 \mathrm{~s}$, $0.07 \mathrm{~s}, 0.05 \mathrm{~s}, 0.01 \mathrm{~s})$; (a) $L_{0}$; (b) $\gamma$; (c) RMSE.

between $5 \mathrm{~V}$ and $15 \mathrm{~V}$ seems likely equal. However, this difference changes when input voltage is $75 \mathrm{~V}$. Creep displacements vary from $0 \mu \mathrm{m}$ to $0.361 \mu \mathrm{m}$, from $0 \mu \mathrm{m}$ to $0.551 \mu \mathrm{m}$, and from $0 \mu \mathrm{m}$ to $0.842 \mu \mathrm{m}$ as the heights of staircase voltage are $3 \mathrm{~V}$, $5 \mathrm{~V}$, and $15 \mathrm{~V}$, respectively. Due to the change of direction or reset function, creep varies insignificantly when input voltage is $60 \mathrm{~V}$. The minimum creep displacement is $-0.150 \mu \mathrm{m}$, $-0.180 \mu \mathrm{m}$, and $-0.220 \mu \mathrm{m}$ as the heights of staircase voltage are $3 \mathrm{~V}, 5 \mathrm{~V}$, and $15 \mathrm{~V}$, respectively. As the same thing in the ascending stage, absolute creep displacement becomes larger when input voltage decreases in descending stage. When input voltage is $0 \mathrm{~V}$, creep displacements vary from $0 \mu \mathrm{m}$ to $-0.451 \mu \mathrm{m}$, from $0 \mu \mathrm{m}$ to $-0.731 \mu \mathrm{m}$, and from $0 \mu \mathrm{m}$ to $-1.232 \mu \mathrm{m}$ as the heights are $3 \mathrm{~V}, 5 \mathrm{~V}$, and $15 \mathrm{~V}$, respectively.

\section{Parameters Identification}

To compare (1) with (2), both equations are used in parameters identification.

4.1. Different Duration. The corresponding displacement data are chosen from one staircase input voltage cycle, $3 \mathrm{~V}-75 \mathrm{~V}-0 \mathrm{~V}$. The staircase voltages are set $3 \mathrm{~V}$ height with different durations. In (1), $L_{0}$ is a real displacement and kept positive and $\gamma$ is either positive or negative in the procedure of identification. The result is shown in Figure 9.

It is observed that different durations are the same as different input voltage frequencies, and then different durations make the hysteresis curve rotate clockwise as shown in Figure 9(a). The absolute maximum values of $\gamma$ increase fast with the step duration decrease as in Figure 9(b) and $\gamma$ is -0.3069 when duration is $0.01 \mathrm{~s}$.

It is found that the relation between $L_{0}$ and staircase voltage is conic in ascending stage and the radius of conic becomes larger with the decreasing duration of staircase voltage; however, the relation between $L_{0}$ and staircase voltage is more linear than conic in descending stage. The mean squared error is $4.406 e-4$ by fitting a line with the least square criterion in descending stage.

$\gamma$ is a butterfly-shape complex hysteretic parameter in Figure 10(b), when the duration is $1 \mathrm{~s}$; however, its range decreases rapidly. The mean of $\gamma$ also decreases when duration decreases. $\gamma$ has a very clear rule that it converges to around 0.21 when the duration is $0.01 \mathrm{~s}$.

The maximum RMSE is 0.016 in Figure 10(c) when staircase duration is $1 \mathrm{~s}$, and it is 0.015 when staircase duration is $0.01 \mathrm{~s}$. As the staircase duration is descending, the RMSE ranges from 0.016 to 0.002 . This means that modeling precision varies a little in different durations. Comparing RMSE in Figure 9(c) with that in Figure 10(c), there are only little different RMSE points. This means both models have the same modeling precision.

4.2. Different Height. Just as that in Section 4.1, the same procedure is done in this subsection. In (1), $L_{0}$ is a real 


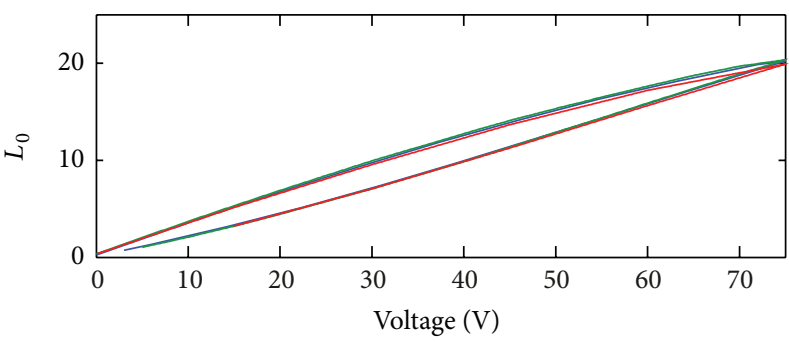

(a)

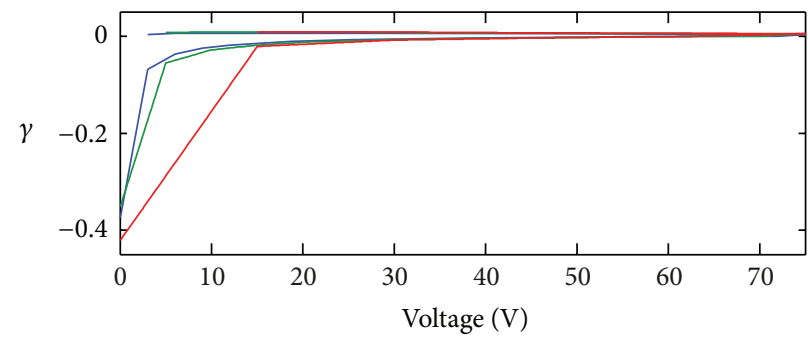

(b)



(c)

FIGURE 11: Parameters distribution of classical log-type creep with $1 \mathrm{~s}$ duration and different heights $H_{d}, H_{d} \in(3 \mathrm{~V}, 5 \mathrm{~V}, 15 \mathrm{~V})$; (a) $L_{0}$; (b) $\gamma$; (c) RMSE.

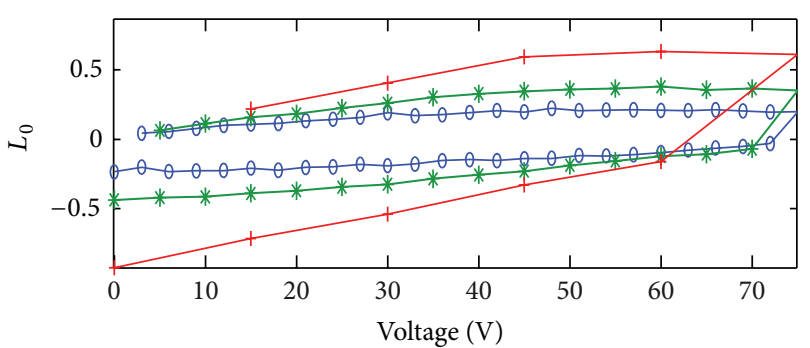

(a)

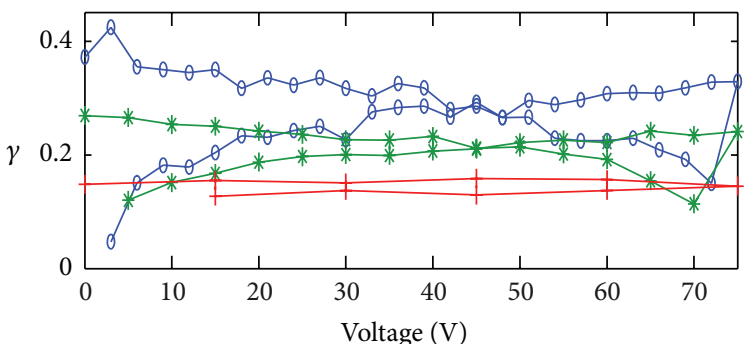

(b)

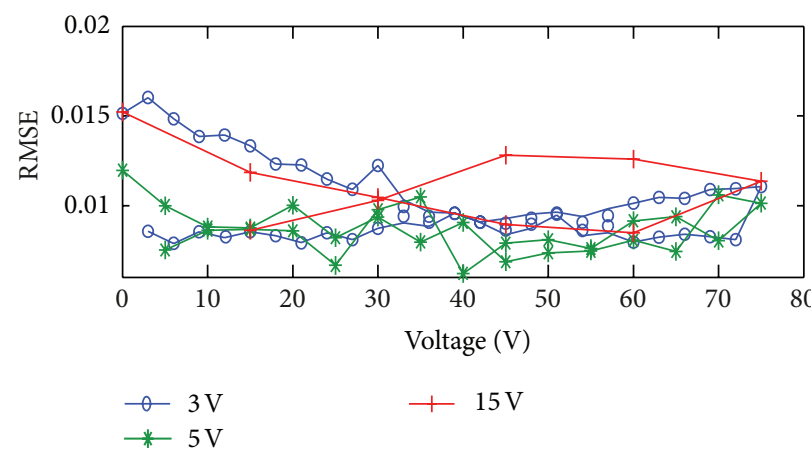

(c)

FIGURE 12: Parameters distribution of creep with different heights of staircase voltage. (a) $L_{0}$; (b) $\gamma$; (c) RMSE.

displacement and kept positive, and $\gamma$ is either positive or negative in the procedure of identification. The results are shown in Figure 11. Comparing with different durations, there are small impacts on $L_{0}$ under different heights of staircase voltages as illustrated in Figure 11(a). However, $\gamma$ in
Figure 11(b) is sensitive to different heights, especially when the input voltage is low in descending stage. Model validity can be verified by Figure 11(c).

$L_{0}$ is a series of anticlockwise curves with height increasing as in Figure 12(a). As the height is larger, the increment 
of $L_{0}$ is larger. Then when input voltage is $0 \mathrm{~V}$ or $75 \mathrm{~V}$, the absolute $L_{0}$ in the response curve of $15 \mathrm{~V}$ is bigger than that in the response curve of $3 \mathrm{~V}$. Just as the curves in Figure 10(a), those anticlockwise curves can be replaced by conics in the ascending stage and by straight lines in descending stage. Apparently, these lines do not have fixed start point. From Figure 12(b), $\gamma$ seems like being congruent to a constant with the height increasing. This can be interpreted as follows: when the height is $75 \mathrm{~V}$, there is only a log-type creep curve. As that in Figure 10(c), model validity is illustrated in Figure 12(c).

\section{Conclusion}

Based on the experimental data of the stack-type piezoelectric actuator, a modified log-type model is used to describe the creep effect within voltage duration of less than a second. In the model, the hysteresis and the creep effect can be separated and tackled, respectively. Because input signal is discretized into staircase DC voltage in digital control, it is necessary to study the effects of different durations and heights of staircase voltages on creep. A number of experiments have been designed and performed to observe the variation of creep. Firstly, with different durations and different heights of staircase voltage, either decreasing duration or increasing height makes $\gamma$ converge to a constant. Secondly, the relation of $L_{0}$ with input staircase voltage is conic in ascending stage, and it is linear in descending stage when duration is small enough. Furthermore, $L_{0}$ has its own constant endpoint in ascending stage and in descending stage.

\section{Acknowledgments}

This work is supported by the National Nature Science Foundation of China (no. 61174044) and partially supported by the Nature Science Found of Shandong Province, China (no. ZR2010FM018).

\section{References}

[1] M. A. Janaideh, S. Rakheja, and C. Y. Su, "Experimental characterization and modeling of rate-dependent hysteresis of a piezoceramic actuator," Mechatronics, vol. 19, no. 5, pp. 656-670, 2009.

[2] S. Devasia, E. Eleftheriou, and S. O. R. Moheimani, "A survey of control issues in nanopositioning," IEEE Transactions on Control Systems Technology, vol. 15, no. 5, pp. 802-823, 2007.

[3] D. A. Hall, "Nonlinearity in piezoelectric ceramics," Journal of Materials Science, vol. 36, no. 19, pp. 4575-4601, 2001.

[4] D. Zhou and M. Kamlah, "Room-temperature creep of soft PZT under static electrical and compressive stress loading," Acta Materialia, vol. 54, no. 5, pp. 1389-1396, 2006.

[5] H. Jung, J. Y. Shim, and D. Gweon, "Tracking control of piezoelectric actuators," Nanotechnology, vol. 12, no. 1, pp. 1420, 2001.

[6] D. Croft, G. Shedd, and S. Devasia, "Creep, hysteresis, and vibration compensation for piezoactuators: atomic force microscopy application," in Proceedings of the American Control Conference, vol. 3, pp. 2123-2128, June 2000.
[7] Q. Xu and Y. Li, "Micro-/nanopositioning using model predictive output integral discrete sliding mode control," IEEE Transactions on Industrial Electronics, vol. 59, pp. 1161-1170, 2012.

[8] Q. Xu and Y. Li, "Model predictive discrete-time sliding mode control of a nanopositioning piezostage without modeling hysteresis," IEEE Transactions on Control Systems Technology, vol. 20, pp. 983-994, 2012.

[9] K. K. Leang and S. Devasia, "Feedback-linearized inverse feedforward for creep, hysteresis, and vibration compensation in AFM piezoactuators," IEEE Transactions on Control Systems Technology, vol. 15, no. 5, pp. 927-935, 2007.

[10] S. Vieira, "the behavior and calibration of some piezoelectirc ceramics used in the STM," IBM Journal of Research and Development, vol. 30, no. 5, pp. 553-556, 1986.

[11] H. Jung, J. Y. Shim, and D. Gweon, "New open-loop actuating method of piezoelectric actuators for removing hysteresis and creep," Review of Scientific Instruments, vol. 71, no. 9, pp. 34363440, 2000.

[12] H. Jung and D. G. Gweon, "Creep characteristics of piezoelectric actuators," Review of Scientific Instruments, vol. 71, no. 4, pp. 1896-1900, 2000.

[13] H. Janocha and K. Kuhnen, "Real-time compensation of hysteresis and creep in piezoelectric actuators," Sensors and Actuators A, vol. 79, no. 2, pp. 83-89, 2000.

[14] B. Mokaberi and A. A. G. Requicha, "Compensation of scanner creep and hysteresis for AFM nanomanipulation," IEEE Transactions on Automation Science and Engineering, vol. 5, no. 2, pp. 197-206, 2008.

[15] K. Kuhnen and P. Krejci, "Compensation of complex hysteresis and creep effects in piezoelectrically actuated systems-a new Preisach modeling approach," IEEE Transactions on Automatic Control, vol. 54, no. 3, pp. 537-550, 2009.

[16] F. Wolf, A. Sutor, S. J. Rupitsch, and R. Lerch, "Modeling and measurement of creep- and rate-dependent hysteresis in ferroelectric actuators," Sensors and Actuators A, vol. 172, pp. 245-252, 2011.

[17] K. Kuhnen, "Modelling, identification, and compensation of complex hysteretic and $\log (\mathrm{t})$-type creep nonlinearities," Control and Intelligent Systems, vol. 33, no. 2, pp. 134-147, 2005.

[18] E. M. Bourim, H. Y. Kim, J. S. Yang et al., "Creep behavior of undoped and La-Nb codoped PZT based micro-piezoactuators for micro-optical modulator applications," Sensors and Actuators A, vol. 155, no. 2, pp. 290-298, 2009.

[19] O. Guillon, F. Thiébaud, P. Delobelle, and D. Perreux, "Compressive creep of PZT ceramics: experiments and modelling," Journal of the European Ceramic Society, vol. 24, no. 9, pp. 25472552, 2004.

[20] T. Fett and G. Thun, "Determination of room-temperature tensile creep of PZT," Journal of Materials Science Letters, vol. 17, no. 22, pp. 1929-1931, 1998.

[21] J. Minase, T. F. Lu, B. Cazzolato, and S. Grainger, "A review, supported by experimental results, of voltage, charge and capacitor insertion method for driving piezoelectric actuators," Precision Engineering, vol. 34, no. 4, pp. 692-700, 2010.

[22] L. Huang, Y. T. Ma, Z. H. Feng, and F. R. Kong, "Switched capacitor charge pump reduces hysteresis of piezoelectric actuators over a large frequency range," Review of Scientific Instruments, vol. 81, no. 9, Article ID 094701, 2010.

[23] Y. T. Ma, L. Huang, Y. B. Liu, and Z. H. Feng, "Note: creep character of piezoelectric actuator under switched capacitor 
charge pump control," Review of Scientific Instruments, vol. 82, no. 4, Article ID 046106, 2011.

[24] P. Krejci and K. Kuhnen, "Inverse control of systems with hysteresis and creep," IEE Proceedings: Control Theory and Applications, vol. 148, no. 3, pp. 185-192, 2001.

[25] H. M. S. Georgiou and R. B. Mrad, "Dynamic electromechanical drift model for PZT," Mechatronics, vol. 18, no. 2, pp. 81-89, 2008. 


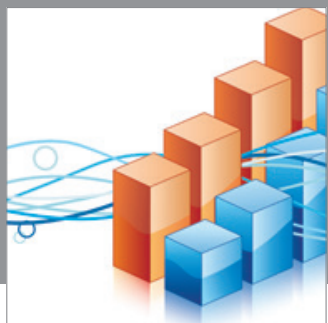

Advances in

Operations Research

mansans

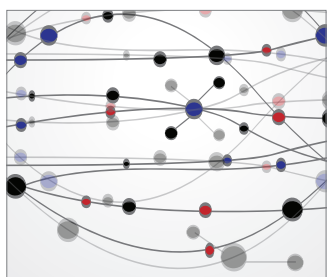

The Scientific World Journal
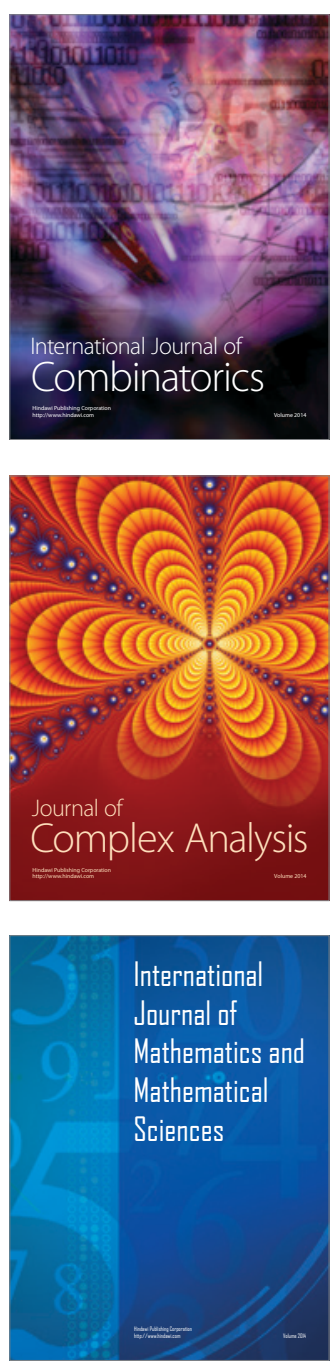
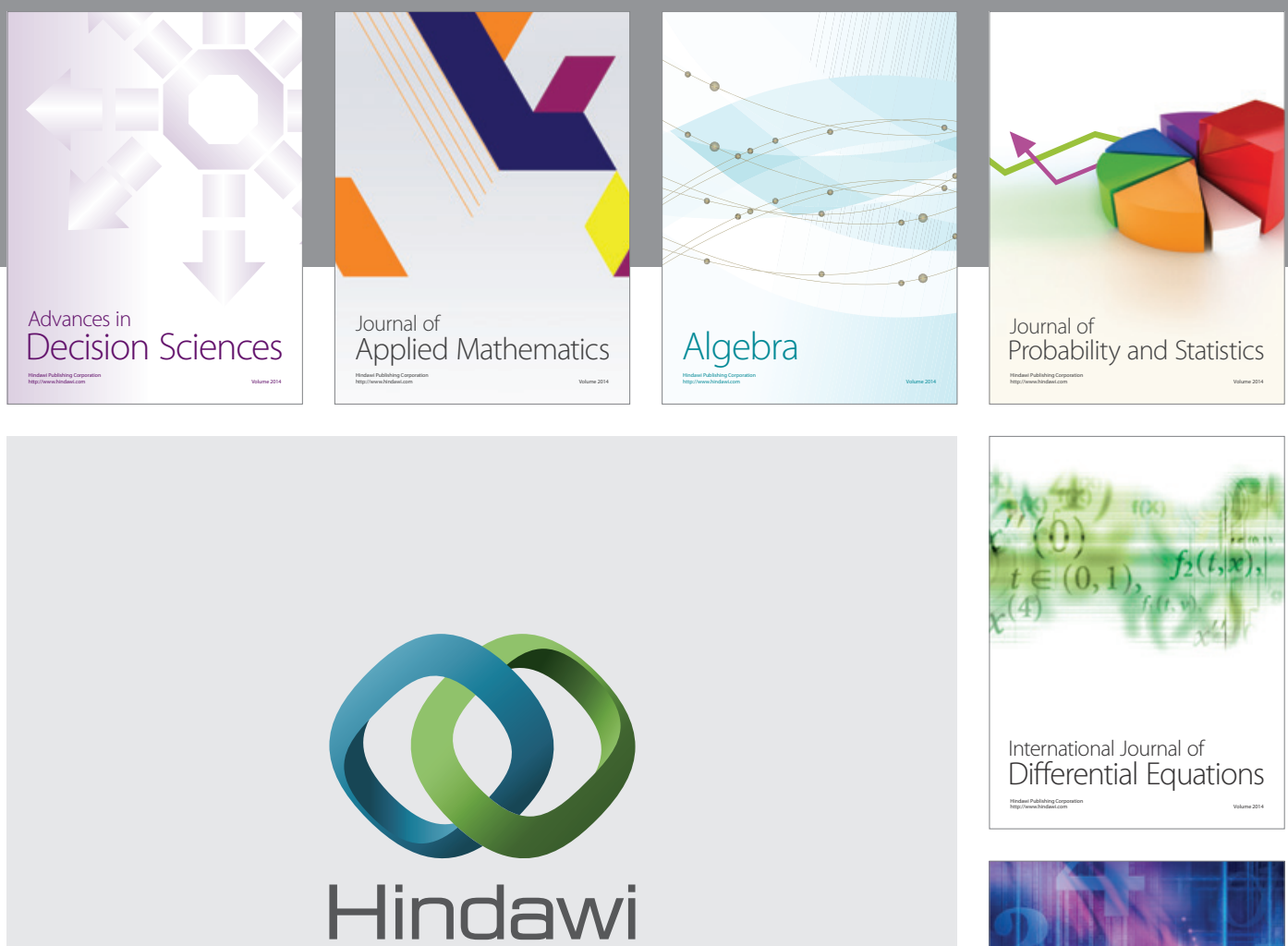

Submit your manuscripts at http://www.hindawi.com
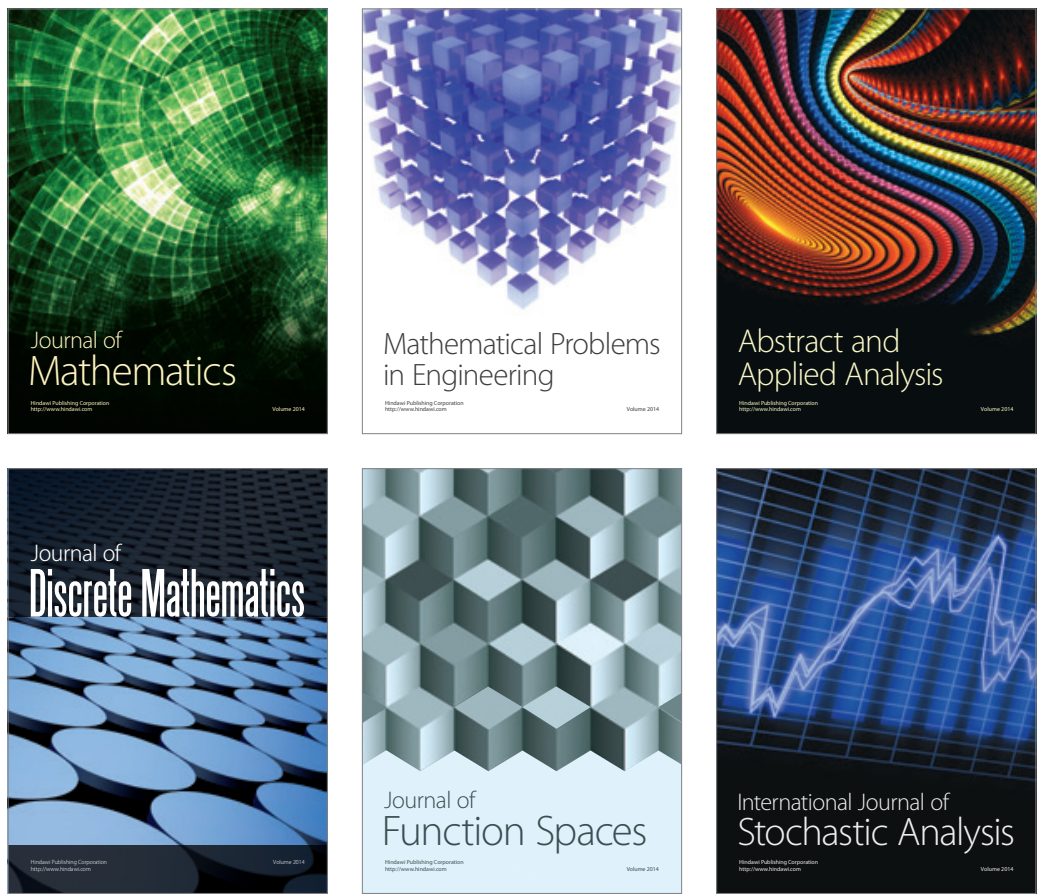

Journal of

Function Spaces

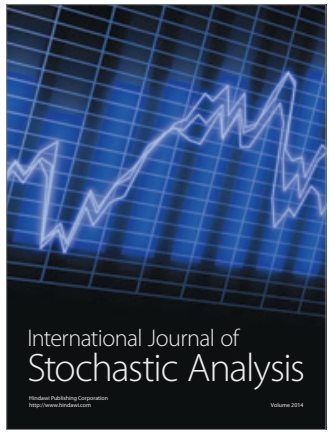

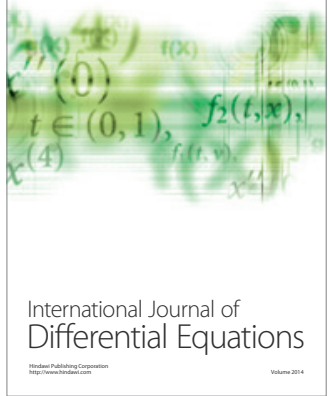
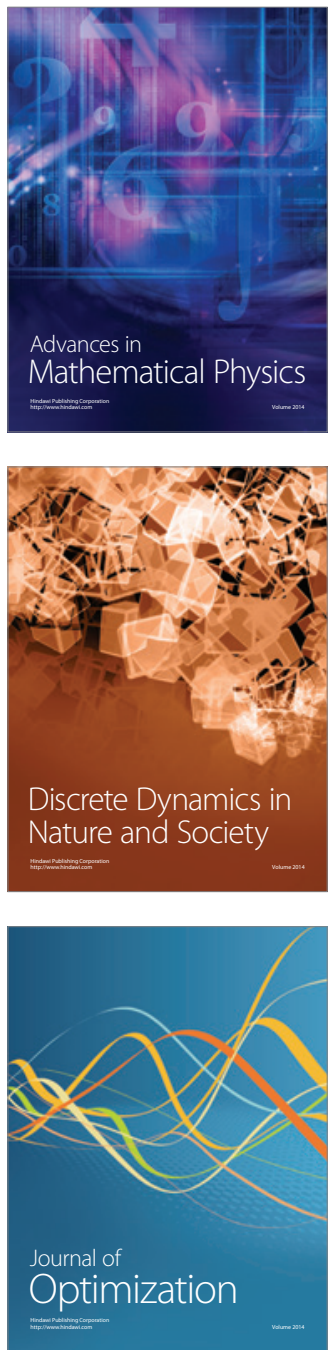